\title{
The impact of dual antiplatelet therapy administration on the risk of bleeding complications during coronary artery bypass surgery
}

\author{
Paolo Nardi, Calogera Pisano, Maria Turturici, Fabio Bertoldo, Vito Renato Maggio, Carlo Bassano, \\ Dario Buioni, Antonio Scafuri, Claudia Altieri, Giovanni Ruvolo
}

Cardiac Surgery Division, Tor Vergata University Hospital, Rome, Italy

Kardiochirurgia i Torakochirurgia Polska 2021; 18 (3): 145-151

\begin{abstract}
Introduction: Dual antiplatelet therapy reduces the risk of cardiovascular death, myocardial infarction and recurrence of adverse ischemic events in patients affected by acute coronary syndromes, but in patients urgently needing coronary artery surgery it can increase the risk of severe perioperative bleeding complications.

Aim: We evaluated the impact of dual antiplatelet therapy (DAPT) based on acetylsalicylic acid plus clopidogrel or ticagrelor in patients undergoing coronary artery bypass grafting (CABG).

Material and methods: Three hundred and thirty-three patients underwent coronary artery bypass grafting with DAPT discontinuation $>72$ hours or $3-4$ days (group $A, n=159$ ), $48-72$ hours or $2-3$ days (group $B, n=126$ ), $<24$ hours or $0-1$ day (group $C$, $n=24)$ prior to $C A B G$.

Results: Operative mortality was $1.87 \%$ (group A), 0.79\% (group B), absent (group C). The incidence of mediastinal re-exploration was $1.25 \%$ or 2 patients (group A), $1.59 \%$ or 2 patients (group B), $8.33 \%$ or 4 patients (group C) ( $p=0.01$ ). Group C showed postoperatively a greater incidence of a blood loss greater than $500 \mathrm{ml}$ at 6 hours and a blood loss from chest tube drainages significantly higher at 6 and 24 hours $(p<0.01)$. Multivariate analysis showed that ongoing ticagrelor intake in group $C(H R=42.4$; $p=0.02)$ and group $C(H R=6.9 ; p=0.04)$ were the only independent predictors of surgical re-exploration. In group $C$, surgical re-exploration was $2.56 \%$ or $1 / 39$ patients taking clopidogrel, $33.3 \%$ or $3 / 9$ patients taking ticagrelor $(p=0.002)$.

Conclusions: Dual antiplatelet therapy ongoing until 1 day or 24 hours before CABG showed a significantly increased risk of bleeding complications in comparison with its discontinuation at 2-3 and > 3-4 days before, respectively. Major blood loss and surgical re-exploration were not associated with increased risk of operative all-cause or bleeding-related mortality. As expected, taking ticagrelor compared with clopidogrel in the short interval confers a higher risk of bleeding complications.
\end{abstract}

Key words: dual antiplatelet therapy, coronary artery bypass grafting, $\mathrm{P}_{2} \mathrm{Y}_{12}$ inhibitors.

\section{Introduction}

Dual antiplatelet therapy (DAPT) with acetylsalicylic acid (ASA) and $\mathrm{P}_{2} \mathrm{Y}_{12}$ inhibitors represents the standard of care of treatment for acute coronary syndromes with or without ST elevation. Acetylsalicylic acid and thienopyridines, i.e., clopidogrel (Plavix, Sanofi S.p.A.), are currently administered to prevent cardiovascular death, myocardial infarction, and recurrence of adverse ischemic events [1-5]. A more recently introduced antiplatelet drug is ticagrelor (Brilique, AstraZeneca S.p.A.), which was approved for use in the European Union in 2010 and in the United States in 2011. Like thienopyridines, ticagrelor is an antiplatelet agent that inhibits the adenosine diphosphate (ADP) $\mathrm{P}_{2} \mathrm{Y}_{12}$ platelet receptor. Unlike clopidogrel, which carries out its pharmacological action irreversibly, ticagrelor allows the blockage of the ADP receptor in a reversible way. In comparison with clopidogrel, ticagrelor does not need hepatic activation, is independent of the activity of cytochrome enzymes with a half-life of 7-8.5 hours, and, after its discontinuation, allows a faster offset of platelet inhibition. As compared with clopidogrel, ticagrelor administration has been shown to reduce the rate of cardiac death, myocardial infarction, and stroke [6-8].

Varenhorst et al. [9] analyzing data from the Platelet inhibition and patient Outcomes (PLATO) study in 1,261 patients undergoing coronary artery bypass grafting found that ticagrelor was associated with fewer deaths from cardiovascular, bleeding, and infection complications. Based on these effective results, ticagrelor is now recommended by the Guidelines of the European Society of Cardiology as a standard therapy in patients with acute coronary syn-

Address for correspondence: Calogera Pisano, Cardiac Surgery Division, Tor Vergata University Hospital, Viale Oxford 81, 00133 Rome, Italy, phone: +39 (06) 20903536, fax: +39 (06) 20903538, e-mail: lindapisano82@gmail.com

Received: 12.02 .2021 , accepted: 18.04 .2021$. 
dromes and those at moderate-to-severe risk of ischemic events at 12 months.

However, patients receiving DAPT and that urgently need coronary artery bypass grafting $(\mathrm{CABG})$ have a high risk of severe perioperative bleeding complications [10]. The ESC and EACTS Guidelines on myocardial revascularization recommend suspension at least 5 days for clopidogrel and 3 days for ticagrelor prior to CABG surgery [4]. However, it is not possible for all patients to perform CABG waiting for a period of 3-5 days after the interruption of DAPT, because many patients present with post-myocardial infarction angina or a coronary artery anatomical picture at high risk of adverse events, thus requiring CABG during ongoing DAPT, or requiring surgery after the initial ticagrelor or clopidogrel loading dose [11]. The evidence on the optimal timing of discontinuation is limited in the literature. Excessive bleeding in the postoperative period may require massive blood transfusion and lead to life-threating complications such as low output cardiac syndrome, respiratory failure and pneumonia, deep sternal wound infections, or cardiac tamponade, so that the mortality rate after surgical re-exploration for bleeding reaches $8-25 \%$ [12].

\section{Aim}

The aim of our study was to evaluate the risk of perioperative bleeding complications after CABG in patients preoperatively treated with DAPT consisting of acetylsalicylic acid plus clopidogrel or ticagrelor administration, stratified by the interval of drug discontinuation. We analyzed the risk factors for blood loss from the thoracic drainage tubes within 6-24 hours, the need for mediastinal re-exploration, trying to define which may be the safest minimum interval of discontinuation in order to avoid the increased risk of bleeding. We also analyzed whether postoperative bleeding and the need for surgical re-exploration caused an increased risk of operative mortality.

\section{Material and methods}

Between January 2017 and December 2018, 333 patients (mean age: 66 ; range: $39-58$, years; males 288 or $86.5 \%$ ) affected by multivessel and/or left main stem coronary artery disease underwent isolated CABG at the Cardiac Surgery Unit of the Tor Vergata University Hospital. On-pump CABG was performed in 307 patients or $92.2 \%$, off-pump CABG in 26 patients or $7.8 \%$. The study was designed to be retrospective, and was approved by the local Institutional Review Board. All patients gave their informed surgical consent.

\section{Antiplatelet therapy management, study groups, and surgical data}

To organize our study, we retrospectively considered the patients who were consecutively operated for isolated CABG, both those operated on electively and those operated on urgently. In patients operated on electively, i.e., after 3-4 days from hospitalization, we interrupted ASA (100 mg per os, daily) and other antiplatelet agents once admitted to our ward, and we administered enoxaparin sodi- um subcutaneously twice daily on the basis of the subject's weight and renal function. For patients undergoing urgent CABG, such as in presence of high-risk anatomic conditions of the coronary arteries, recently implanted stent/s, acute phase of coronary artery syndrome, recent myocardial infarction, or post-infarction unstable angina, we could not interrupt single or double antiplatelet therapy. When possible, only the single antiplatelet drug administration was maintained, i.e., ASA $100 \mathrm{mg}$ once a day, with suspension of P2Y 12 receptor inhibitors, i.e., clopidogrel and ticagrelor. For patients for whom it was not possible to interrupt the DAPT before CABG, the dosage of clopidogrel remained at $75 \mathrm{mg}$ daily, the dosage of ticagrelor at $90 \mathrm{mg}$ twice daily.

To assess the risk of bleeding complications we retrospectively divided the patients into three study groups, according to the time interval of DAPT (acetylsalicylic acid plus clopidogrel or ticagrelor) discontinuation. The first group (A) consisted of 159 patients in whom it was possible to suspend dual antiplatelet aggregation therapy at least 4 days or $>72$ hours before CABG; the second group (B) included 126 patients in whom DAPT was administered up to 2-3 days or 48-72 hours and then suspended, before surgery; group $C$ consisted of 48 patients in whom DAPT had been discontinued only within 24 hours before CABG or it was still ongoing at the time of surgery.

Access to the heart was obtained through a complete longitudinal sternotomy. On-pump CABG was performed by means of normo-thermic cardiopulmonary bypass and intermittent antegrade warm blood cardioplegia administered every 16-25 minutes, or cold crystalloid St. Thomas cardioplegic solution administered every 30-35 minutes. Cardiopulmonary bypass was performed by means of a Sorin Monolyth-Pro (Sorin Biomedica; Turin, Italy) or Capiox (Terumo Cardiovascular System; Borken, Germany) membrane oxygenator and a Stockert roller pump (Stockert Instrumente; Munich, Germany).

Exclusion criteria to perform off-pump CABG included severe left ventricular dysfunction, cardiac dilation, i.e. expressed by a left ventricular end-diastolic diameter greater than $60 \mathrm{~mm}$, distal diffuse narrowing of coronary arteries, intra-myocardial course of the left descending coronary artery, or in presence of perioperative hemodynamic instability. In off-pump CABG patients, the left anterior descending artery plus minus its diagonal branches was bypassed as the first vessel, followed by the revascularization of the right coronary artery and the left circumflex artery systems. Stabilization was obtained with the aid of suction stabilizers (Octopus and Starfish; Medtronic Inc; Minneapolis, MN; USA, and Acrobat and X-pose; Guidant Co; Boston Scientific, Boston, MS, USA). Perfusion during the distal anastomoses was maintained using intravascular 1.5-2 mm shunts (Clearview, Medtronic Inc.; Minneapolis, MN; USA). During off-pump CABG, monitoring of cardiac function was obtained with trans-esophageal echocardiography and insertion of a Swan-Ganz catheter. The left internal thoracic artery as "in situ graft" was the conduit of choice for left anterior descending artery revascularization. In all patients at the end of the operation before the sternal 
closure, two mediastinal chest drainage tubes and one left pleural drainage tube were placed.

\section{Data analysis}

In the three groups of patients we evaluated the average blood loss from the thoracic drainage tubes, calculated at 6 and 24 hours after CABG, the incidence of blood loss greater than $500 \mathrm{ml}$ at 6 hours and 24 hours postoperatively, the incidence of surgical mediastinal re-exploration for bleeding, and need for blood cell and platelet concentrate transfusions. Perioperative myocardial infarction was defined by the increase in the post-operative period of troponin I higher than $20 \mathrm{ng} / \mathrm{ml}$ associated with a CK-MB value more than $10 \%$ of total CPK, and the onset of ECG new anomalies. Postoperative low output cardiac syndrome was defined by a cardiac index value less than $2.0 \mathrm{l} / \mathrm{min} / \mathrm{m}^{2}$ requiring inotropic support for a period greater than 24 hours.

We also analyzed the incidence of postoperative major non-cardiac complications, i.e. pulmonary, neurological and renal complications. Operative mortality included in-hospital death after operation at any time or within 30 days after discharge. In the perioperative period, the indication for the transfusion of red blood cell units was given in the presence of a hemoglobin value less than $9.0 \mathrm{~g} / \mathrm{dl}$; that for platelet concentrate transfusion was based on mediastinal bleeding, on the platelet count value, or on the clinical decision of the anesthesiologist.

\section{Statistical analysis}

Statistical analysis was performed using Stat View 4.5 (SAS Institute Inc, Abacus Concepts, Berkeley, CA). We analyzed preoperative and perioperative variables, including age, gender, EuroSCORE II Risk Stratification System, previous myocardial infarction, smoking habit, arterial hypertension, diabetes mellitus, chronic renal dysfunction, chronic obstructive pulmonary disease, hyperlipidemia, peripheral vascular disease, previous neurological events, preoperative creatinine serum level, the three different study groups defined on the basis of the interruption interval of the double antiplatelet therapy, antiplatelet drugs administration, and need for urgent surgery. Intraoperative variables included the mean number of grafts per patient, cardiopulmonary bypass and aortic cross-clamp times, the choice of off-pump or on-pump surgery, and the use of single or bilateral internal thoracic artery. Univariate analysis was performed to detect the potential risk factors for blood loss greater than $500 \mathrm{ml}$ at 6 and 24 hours after coronary artery bypass grafting. Risk factor analysis to detect independent predictors for the need of mediastinal re-exploration for bleeding was performed using the univariate and the logistic regression models. All other continuous values were expressed as mean plus or minus one standard deviation of the mean. All $p$-values less than 0.05 were considered statistically significant, both in the comparison of the measured variables between the three study groups, and in the univariate and multivariate analysis.

\section{Results}

Preoperative characteristics of the three groups of patients are reported in Table I. A significant difference was found for the preoperative length of stay, which was, as expected, shorter in groups $B$ and $C$ in comparison with group $A$ due to the need for urgent surgery. As compared

Table I. Preoperative characteristics

\begin{tabular}{|c|c|c|c|c|}
\hline Characteristic & $\begin{array}{l}\text { Group A } \\
(n=159)\end{array}$ & $\begin{array}{l}\text { Group B } \\
(n=126)\end{array}$ & $\begin{array}{l}\text { Group C } \\
(n=48)\end{array}$ & $P$-value \\
\hline Age [years] & $67 \pm 8.5$ & $68 \pm 9.8$ & $65 \pm 11.4$ & NS \\
\hline Sex (male), $n$ (\%) & $141(89)$ & $104(83)$ & $43(90)$ & 0.256 \\
\hline EuroSCORE II (\%) & $2.7 \pm 2.0$ & $2.6 \pm 2.4$ & $2.9 \pm 2.6$ & NS \\
\hline Hypertension, $n(\%)$ & $113(71)$ & $97(78)$ & $35(78)$ & 0.392 \\
\hline Active smokers, $n(\%)$ & $47(35)$ & $42(27)$ & $13(31)$ & 0.352 \\
\hline Previous smoking habit, $n(\%)$ & $109(69)$ & $76(60)$ & $29(64)$ & 0.395 \\
\hline Diabetes mellitus, $n$ (\%) & $68(43)$ & $57(46)$ & $17(38)$ & 0.655 \\
\hline Hyperlipidemia, $n$ (\%) & $84(53)$ & $64(51)$ & $30(67)$ & 0.184 \\
\hline Chronic renal dysfunction, $n(\%)$ & $47(30)$ & $51(41)$ & $15(33)$ & 0.149 \\
\hline Serum creatinine level [mg/dl] & $1.3 \pm 1.5$ & $1.3 \pm 1.5$ & $1.0 \pm 0.3$ & NS \\
\hline Chronic obstructive pulmonary disease, $n(\%)$ & $16(10)$ & $15(12)$ & $6(13)$ & 0.812 \\
\hline Peripheral vascular disease, $n(\%)$ & $13(8.2)$ & $14(11)$ & $2(4.2)$ & 0.365 \\
\hline Carotid artery disease, $n(\%)$ & $11(7.0)$ & $8(6.3)$ & $2(4.2)$ & 0.831 \\
\hline Previous stroke or hemorrhage, $n(\%)$ & $6(3.8)$ & $2(1.6)$ & 0 & 0.252 \\
\hline Previous myocardial infarction, $n(\%)$ & $42(26)$ & $42(34)$ & $18(38)$ & 0.177 \\
\hline $\begin{array}{l}\text { Recent (<30 days) myocardial infarction, unstable angina, } \\
\text { high-risk anatomy of diseased coronary artery vessels, } n(\%)\end{array}$ & $72(45)$ & $52(41)$ & $48(100)$ & $0.001^{\star}$ \\
\hline Preoperative length of stay [days] & $5.6 \pm 4.5$ & $3.7 \pm 3.4$ & $1.2 \pm 0.9$ & $\begin{array}{l}<0.001^{\S} \\
<0.0001^{\dagger}\end{array}$ \\
\hline
\end{tabular}

EuroSCORE - European System for Cardiac Operation Risk Evaluation. NS - not significant, for all measurements. ${ }^{*} P$-value significant for group $C$ versus groups $\mathrm{A}$ and $\mathrm{B} ;{ }^{\S} p$-value significant for group $\mathrm{A}$ versus group $\mathrm{B} ;{ }^{\dagger} p$-value significant for group $\mathrm{A}$ versus group $\mathrm{C}$, for group $\mathrm{B}$ versus group $\mathrm{C}$. 
The impact of dual antiplatelet therapy administration on the risk of bleeding complications during coronary artery bypass surgery

Table II. Preoperative coagulation profile and blood cell count parameters

\begin{tabular}{lcccc} 
Variable & $\begin{array}{r}\text { Group A } \\
(n=159)\end{array}$ & $\begin{array}{c}\text { Group B } \\
(n=126)\end{array}$ & $\begin{array}{c}\text { Group C } \\
(n=48)\end{array}$ & P-value \\
INR & $1.07 \pm 0.1$ & $1.20 \pm 1.0$ & $1.05 \pm 0.1$ & NS \\
\hline PT (\%) & $89.5 \pm 14$ & $92.2 \pm 11$ & $92.3 \pm 8.9$ & NS \\
\hline PT [s] & $12.6 \pm 1.7$ & $12.4 \pm 1.1$ & $12.3 \pm 0.9$ & NS \\
\hline PTT (ratio) & $1.10 \pm 0.4$ & $1.00 \pm 0.1$ & $1.00 \pm 0.2$ & NS \\
\hline PTT [s] & $35.8 \pm 13$ & $34.7 \pm 4.9$ & $33.5 \pm 7.3$ & NS \\
\hline Fibrinogen $[\mathrm{mg} / \mathrm{dl}]$ & $425 \pm 173$ & $419 \pm 150$ & $450 \pm 172$ & NS \\
\hline Anti-thrombin III $(\%)$ & $95.3 \pm 34$ & $95.1 \pm 14$ & $98.5 \pm 24$ & NS \\
\hline Hemoglobin $[\mathrm{g} / \mathrm{dl}]$ & $13.4 \pm 1.7$ & $13.3 \pm 1.9$ & $13.3 \pm 1.6$ & NS \\
\hline Hematocrit $(\%)$ & $43.8 \pm 3.2$ & $41.2 \pm 5.4$ & $40.7 \pm 4.9$ & NS \\
\hline Erythrocytes $\left[\times 10^{6} / \mu \mathrm{l}\right]$ & $4.7 \pm 0.6$ & $4.6 \pm 0.7$ & $4.5 \pm 0.7$ & $\mathrm{NS}$ \\
\hline Leucocytes $\left[\times 10^{3} / \mu \mathrm{l}\right]$ & $8.4 \pm 3.1$ & $7.9 \pm 2.2$ & $8.8 \pm 3.1$ & NS \\
\hline Platelets $\left[\times 10^{3} / \mu \mathrm{l}\right]$ & $233 \pm 68$ & $239 \pm 71$ & $240 \pm 72$ & NS \\
\hline
\end{tabular}

INR - international normalized ratio, PT - prothrombin time, PTT - partial thromboplastin time, NS - not significant, for all measurements.

with groups $A$ and $B$, group $C$ required more frequently the need for emergency or urgent CABG due to the presence of post-infarction unstable angina and/or the high-risk anatomy profile of the coronary artery vessels $(p=0.001$, for both comparisons). Preoperative laboratory examinations did not show significant differences among the three groups of patients (Table II). There were no statistically significant differences among the intraoperative analyzed variables and postoperative cardiac and major non-cardiac complications in the three groups of patients (Table III). Overall operative mortality was $1.20 \%$ or 4 patients; $1.87 \%$ in group $A, 0.79 \%$ in group $B$, absent in group $C$ (Table III). In group A one female patient died due to low output cardiac syndrome, and two male patients died due to respiratory failure and septic shock $(n=1)$ and perioperative myocardial infarction $(n=1)$. In group B 1 male patient, affected preoperatively by severe chronic renal dysfunction, died due to acute kidney failure. The mean duration of the intensive care unit stay and postoperative in-hospital stay were similar between the three groups.

There were no bleeding complication-related deaths in the whole study population (Table IV). The overall incidence of mediastinal re-exploration for bleeding was $2.4 \%$ or 8 patients; $1.25 \%$ or 2 patients in group $A, 1.59 \%$ or 2 patients in group $\mathrm{B}, 8.33 \%$ or 4 cases in group $C(p=0.01)$ (Table IV). Moreover, as compared with groups $A$ and $B$, group $C$ showed postoperatively a greater incidence of blood loss greater than $500 \mathrm{ml}$ at 6 hours and blood loss from chest tube drainages significantly higher 6 and 24 hours after CABG ( $p<0.01$, for all measurements) (Table IV).

The multivariate logistic regression analysis showed that the ongoing ticagrelor intake in group $C$ (hazard ratio $(\mathrm{HR})=42.4 ; 95 \% \mathrm{Cl}: 1.63-1104 ; p=0.024)$ and group $\mathrm{C}(\mathrm{HR}$ $=6.9 ; 95 \% \mathrm{Cl}: 1.01-47.5 ; p=0.048)$ were the only two independent predictors of surgical mediastinal re-exploration for excessive bleeding (Table V). Of note, in group $C$ the incidence of surgical re-exploration was $2.56 \%$ or 1 out of 39 patients taking clopidogrel, and $33.3 \%$ or 3 out of 9 patients taking ticagrelor $\left(\chi^{2}=9.3 ; p=0.002\right)$, respectively.

Patients undergoing mediastinal re-exploration showed significant higher blood loss from chest tube drainages respectively at 6 hours ( $634 \pm 298$ vs. $198 \pm 124 \mathrm{ml} ; p<0.0001)$ and 24 hours ( $884 \pm 401$ vs. $527 \pm 265 \mathrm{ml} ; p=0.002$ ) postoperatively. They required more units of transfused blood per patient ( $12 \pm 21$ vs. $0.8 \pm 1.4$ units; $p<0.0001)$, and need for prolonged intensive care unit stay (7.1 \pm 10 vs. $2.5 \pm 2.9$ days; $p=0.0002$ ) and for total postoperative length of stay (20 \pm 26 vs. $10 \pm 8.0$ days; $p=0.004)$.

\section{Discussion}

In the present study, we analyzed the effect of perioperative DAPT administration in patients undergoing CABG, focusing attention on the time of discontinuation of the antiplatelet aggregation therapy, based on the use

Table III. Intraoperative and postoperative analyzed variables

\begin{tabular}{|c|c|c|c|c|}
\hline Variable & $\begin{array}{l}\text { Group A } \\
(n=159)\end{array}$ & $\begin{array}{l}\text { Group B } \\
(n=126)\end{array}$ & $\begin{array}{l}\text { Group C } \\
(n=48)\end{array}$ & $P$-value \\
\hline Cardiopulmonary bypass time [min] & $102 \pm 35$ & $99.4 \pm 33$ & $109 \pm 46$ & NS \\
\hline Aortic cross-clamp time [min] & $62.6 \pm 23$ & $60.5 \pm 26$ & $66.9 \pm 30$ & NS \\
\hline Left internal thoracic artery use, $n(\%)$ & $(87)$ & $(90)$ & $(91)$ & 0.706 \\
\hline Bilateral internal thoracic artery use, $n(\%)$ & $1(0.6)$ & $4(3.2)$ & $2(4.2)$ & 0.178 \\
\hline No. bypass grafts per patient (mean value) & $2.8 \pm 0.8$ & $2.7 \pm 0.8$ & $2.7 \pm 0.9$ & NS \\
\hline Norepinephrine use > 24 hours and/or inotropic treatment for LOCS, $n$ (\%) & $35(22)$ & $21(17)$ & $13(27)$ & 0.241 \\
\hline Myocardial infarction, $n(\%)$ & 0 & 0 & 0 & - \\
\hline Pulmonary complications, $n(\%)$ & $1(0.6)$ & $1(0.8)$ & 0 & 0.834 \\
\hline Neurological damage, $n(\%)$ & $1(0.6)$ & 0 & 0 & - \\
\hline Acute kidney injury, $n(\%)$ & 0 & $3(2.4)$ & 0 & 0.089 \\
\hline In-ICU stay [days] & $2.7 \pm 3.9$ & $2.7 \pm 2.9$ & $2.9 \pm 1.6$ & NS \\
\hline Postoperative length of stay [days] & $11 \pm 10$ & $9.7 \pm 7.9$ & $10 \pm 5.0$ & NS \\
\hline Operative mortality, $n$ (\%) & $3(1.87)$ & $1(0.79)$ & 0 & 0.499 \\
\hline
\end{tabular}

ICU - intensive care unit, LOCS - low output cardiac syndrome, NS - not significant, for all measurements. 
Table IV. Bleeding-related complications

\begin{tabular}{|c|c|c|c|c|}
\hline Variable & $\begin{array}{l}\text { Group A } \\
(n=159)\end{array}$ & $\begin{array}{l}\text { Group B } \\
(n=126)\end{array}$ & $\begin{array}{l}\text { Group C } \\
(n=48)\end{array}$ & $P$-value \\
\hline Deaths, $n(\%)$ & 0 & 0 & 0 & - \\
\hline Mediastinal re-exploration for bleeding, $n(\%)$ & $2(1.25)$ & $2(1.59)$ & $4(8.33)$ & 0.01 \\
\hline Blood loss from pleural-mediastinal drainage tubes at 6 hours PO [ml] & $198 \pm 135$ & $198 \pm 139$ & $277 \pm 185$ & $\begin{array}{l}0.997 \\
0.002^{\star} \\
0.003^{\star}\end{array}$ \\
\hline Blood loss from pleural-mediastinal drainage tubes at 24 hours PO [ml] & $511 \pm 254$ & $507 \pm 206$ & $698 \pm 409$ & $\begin{array}{c}0.867 \\
0.0002^{\S} \\
<0.0001^{\S}\end{array}$ \\
\hline Blood loss greater than $500 \mathrm{ml}$ at 6 hours PO, $n(\%)$ & $6(3.77)$ & $5(3.97)$ & $9(18.6)$ & 0.0003 \\
\hline No. transfused red blood cell units per patient & $0.7 \pm 1.4$ & $1.3 \pm 4.6$ & $0.8 \pm 1.2$ & NS \\
\hline Platelets transfusion, $n$ (\%) & $4(2.52)$ & $5(3.97)$ & $4(8.33)$ & NS \\
\hline
\end{tabular}

CABG - coronary artery bypass grafting, PO - postoperatively, NS - not significant, for one and for all measurements. * $P$-value significant for group $C$ versus groups $A$ and $B ;{ }^{\S} p$-value significant for group $C$ versus groups $A$ and $B$.

of ticagrelor or clopidogrel in association with ASA. The main finding of our study was that the non-discontinuation of DAPT at least 48 hours or 2 days before CABG, i.e. group $C$ of the studied population of patients, led to significantly greater blood loss at 6 and 24 hours after surgery and conferred a significantly higher risk of surgical mediastinal re-exploration for bleeding. Surgical re-exploration required more blood transfusions and an overall longer postoperative stay. Moreover, in group C, the administration of ticagrelor in comparison with that of clopidogrel was significantly associated with a substantially higher risk of significant bleeding requiring surgical re-thoracotomy (33.3\% vs. 2.6\%). In our study we also found that greater blood loss and the need for re-exploration were not associated with an increased risk of operative mortality or of bleeding complication-related deaths.

Ticagrelor administration was initially analyzed in 18,624 patients affected by acute coronary syndrome enrolled in the PLATO trial; as compared with clopidogrel, ticagrelor led to a significant decrease of cardiovascular events, i.e. deaths from cardiovascular causes, myocardial infarction and stroke at 12 months (9.8\% vs. $11.7 \%$, $p<0.001$ ) [6]. However, ticagrelor was associated with a higher rate of major bleeding, i.e. intracranial bleeding, (4.5\% vs. 3.8\%). A sub-study of the PLATO trial, performed on 1,261 patients with acute coronary syndromes undergoing CABG within 7 days after stopping the study drugs, showed a reduction of operative mortality without an increased risk of bleeding in patients treated with ticagrelor in comparison with clopidogrel. Indeed, the risk of numerous episodes of bleeding with the use of ticagrelor was lower (9 patients versus 27 patients, $p<0.01$ ) [9].

The best results obtained in this study with the use of ticagrelor could have been due to several reasons. Clopidogrel is an irreversible platelet inhibitor, and normal platelet activity is not recovered until 5 to 10 days after its discontinuation. Cessation of clopidogrel is therefore recommended at least 120 hours or 5 days before CABG in order to limit the risk of bleeding $[13,14]$. In contrast, ticagrelor is a reversible $P 2 Y_{12}$ receptor inhibitor with a faster offset of platelet inhibition, i.e.
Table V. Independent risk factors for surgical re-exploration for bleeding (multivariate analysis)

\begin{tabular}{lccc} 
Variable & $\begin{array}{c}\text { Hazard } \\
\text { ratio }\end{array}$ & $95 \% \mathrm{Cl}$ & $P$-value \\
Ongoing ticagrelor intake in Group C & 42.4 & $1.63-1104$ & 0.024 \\
\hline Group C & 6.90 & $1.01-47.5$ & 0.048 \\
\hline $\begin{array}{l}\text { Lower preoperative fibrinogen serum } \\
\text { level }\end{array}$ & 0.90 & $0.98-1.01$ & 0.078 \\
\hline $\begin{array}{l}\text { Lower preoperative anti-thrombin } \\
\text { III serum level }\end{array}$ & 1.00 & $0.99-1.05$ & 0.064 \\
\hline $\begin{array}{l}\text { Higher preoperative creatinine } \\
\text { serum level }\end{array}$ & & & 0.151 \\
\hline Hypertension & & & 0.108 \\
\hline
\end{tabular}

a shorter time interval of drug discontinuation. Moderate-topoor clopidogrel responders have a similar time recovery of platelet function compared with ticagrelor-treated patients after cessation of the treatment. In contrast, about one third of patients with ongoing clopidogrel intake have a high level of platelet inhibition, thus explaining why these patients may be particularly vulnerable to bleeding complications, especially if its administration is not interrupted at least 5 days before surgery, as recommended by the current guidelines [15-17]. Precisely because of the variable anti-aggregation response that patients can present with the intake of clopidogrel, Mahla et al. [18], in 180 elective CABG patients, showed that a strategy based on preoperative platelet function testing to determine the timing of CABG in clopidogrel-treated patients was associated with the same amount of bleeding observed in clopidogrel-naive patients, with about 50\% shorter waiting time than that recommended by the current guidelines. The fact that clopidogrel may not always be effective in its antiplatelet effect has probably occurred in our groups of patients studied, where we observed a lower incidence of surgical bleeding ( $<3 \%)$ than initially assumed, i.e., patient non-responders. Unlike clopidogrel, the antiplatelet efficacy of ticagrelor remained high if it was not suspended at least 48 hours before: in fact, in group C the postoperative bleeding appeared to be higher. Hansson et al. in 
25 patients operated on for urgent CABG found that adenosine diphosphate-induced aggregation was acceptable after 72 hours of ticagrelor discontinuation, with a mean aggregation value of $38 \pm 23$ units, which is above the suggested cut-off of 22 units [8]. Russo et al., among 508 patients affected by acute coronary syndrome treated with clopidogrel $(n=413)$ or ticagrelor $(n=95)$, found that CABG performed within 72 hours after $\mathrm{P}_{2} \mathrm{Y}_{12}$ inhibitor discontinuation was associated with excess bleeding in comparison with 72 hoursto- 5 days and $>5$ days discontinuation $(p \leq 0.001)$ [19]. Retrospective studies in small patient samples have examined the risk of bleeding when ticagrelor was ongoing. Schotola et al., in 32 patients receiving ticagrelor plus ASA and in 49 patients receiving clopidogrel plus ASA, found that in the first 24 hours median blood loss, red blood cell and platelet transfusions, use of prothrombin complex concentrate and fibrinogen, were significantly higher in the ticagrelor-treated patients ( $p<0.05$, for all comparisons) [20]. In this study, although the incidence of surgical re-thoracotomy was greater in the ticagrelor group of patients without statistical significance, the mortality rate was similar. Hansson et al. in 173 patients treated with ASA plus clopidogrel, and 232 with ASA plus ticagrelor, did not find a significant difference in the incidence of major bleeding complications before CABG when either drug was discontinued at 5 days (9.9\% vs. $6.8 \%$ ) or at $2-4$ days ( $25 \%$ vs. $6.3 \%)$. On the other hand, when drugs were discontinued under 24 hours, there was a high incidence of bleeding in patients treated with ticagrelor (41\% vs. 21.7\%) [21]. Gherli et al. analyzing a cohort of acute coronary syndrome patients undergoing CABG from the European Multicenter Study on CABG (E-CABG), treated with ASA or ASA plus ticagrelor (215 matched pairs of patients), found that if ticagrelor was administered until 1 day before $C A B G$, there was an increased risk of severe bleeding (18.2\% vs. 5.9\%) [22]. Vuilliomenet et al. in a sample of 334 patients with acute coronary syndrome analyzed the impact of DAPT discontinuation at 48-72, 24-48, and $<24$ hours, before CABG treated with ASA only $(n=72)$, ASA plus clopidogrel $(n=72)$, prasugrel $(n=68)$ or ticagrelor $(n=122)$. The authors found that discontinuation of ticagrelor or prasugrel for less than 24 hours was associated with significant higher postoperative bleeding and use of blood products $(p<0.001)$ [23].

Holm et al., including 1,293 clopidogrel- and 1,018 ticagrelor-treated patients, found that ticagrelor had a higher incidence of major bleeding when it was discontinued 0 to 2 compared with 3 days before CABG (16\% vs. 2.7\%), and clopidogrel had a higher incidence of major bleeding when discontinued 0 to 3 days compared with 4 to 5 days before CABG (16\% vs. $8.3 \%)$. Thus, they suggested postponing $C A B G$ for at least 3 days after discontinuation of ticagrelor and 4 days after clopidogrel [24].

Similar risk of bleeding correlated with the time interval of the DAPT discontinuation was observed in our study. In group C, without the discontinuation of ticagrelor 24 or less than 24 hours before CABG, we found a 40 -fold increased risk of blood loss greater than $500 \mathrm{ml}$ at 6 hours. More- over, in this subgroup of patients we observed a higher risk of surgical re-thoracotomy, i.e., 3 out of 9 patients, in comparison with the patients of the other 2 groups and those taking clopidogrel. The higher incidence of surgical bleeding while taking dual antiplatelet therapy has been highlighted in a previously published study on a smaller sample of patients [11]. The results of the current, larger study confirm that patients on dual antiplatelet therapy have a significantly higher risk of perioperative bleeding after CABG, both requiring surgical revision, and requiring greater monitoring and attention to specific therapy of bleeding drainage from the chest tubes (Table IV).

The impact of bleeding requiring surgical re-exploration on operative and short-term outcomes was thoroughly analyzed in the Polish national study on a large population of 41,353 patients undergoing isolated CABG [25]. The Investigators found that in patients undergoing re-exploration, i.e. 1,406 (3.4\%), in-hospital mortality was very high in comparison with other patients ( $13.2 \%$ vs. $1.8 \%, p<0.0001)$, as well as the mid-term mortality during 4 years of follow-up ( $p<0.001)$. Surgical re-exploration was found to be an independent predictor of death and all major postoperative complications [25].

In our study, we noted a markedly different risk of bleeding in patients taking ticagrelor than in those taking clopidogrel. In group C the observed greater rate, i.e., 33\% of reexploration in ticagrelor-treated patients in comparison with the lower rate, i.e., $2.6 \%$ in clopidogrel-treated patients, is most likely due to the fact that the time of withdrawal of the $\mathrm{P}_{2} \mathrm{Y}_{12}$-receptor inhibitor is of marked importance for ticagrelor-treated patients, giving the greatest short-term efficacy in platelet inhibition of ticagrelor. Ticagrelor, having a more direct action without the need for liver activation, has showed more power in the anti-aggregation effect than clopidogrel, which can also have non-responder patients; but at the same time, it has a short half-life and reversible binding, beyond which its effect is limited more easily than clopidogrel. However, although the incidence of surgical bleeding was lower in our 39 cases, the greater bleeding from the drainage tubes was still markedly evident also in clopidogrel-treated patients of group $C$. Therefore, as observed in comparison with groups $A$ and $B$, the possibility of suspending the two drugs at least 2 days before $C A B G$ can significantly reduce the risk of bleeding, and, in particular for the ticagrelor-treated patients, the risk of surgical re-exploration.

The present study has several limitations: in fact, it is limited by the small sample of patients; the number of patients in group $C$ who were taking ticagrelor was only 9 , and those taking clopidogrel 39; thus any conclusions should be drawn with caution.

However, based on several scientific publications and on our own experience, when possible, it would be better to postpone the CABG beyond 48 hours, or 2 days, of suspension of the DAPT. Although the cardiologist may argue that submitting the patient taking DAPT to CABG in a short time, i.e., at the end of coronary angiography, with the patient who has just taken the loading dose, is in favor of 
the benefit of preventing life-threatening ischemic events, surgical scientific experiences, including ours, show a clear increase in the risk of bleeding. The surgeon may spend extra time in the operating room waiting for clotting, looking at the bleeding level mark from the mediastinal tubes in the intensive care unit, or receiving the anxious night call necessitating return to the operating room.

\section{Conclusions}

In our experience dual antiplatelet therapy with acetylsalicylic acid plus clopidogrel or ticagrelor ongoing until 1 day or 24 hours before CABG (group C) showed a clearly significant increased risk of bleeding complications in comparison with its discontinuation at 2-3 (group B) and > 3-4 (group A) days before. Major blood loss and surgical re-exploration were not associated with increased risk of operative all-cause or bleeding-related mortality. Taking ticagrelor compared with clopidogrel in the short interval, i.e., less than 1 day, having a more powerful antiplatelet effect, consequently confers a higher risk of bleeding. Therefore, whenever possible, its suspension should be done at least 2 days before CABG.

\section{Disclosure}

The authors report no conflict of interest.

\section{References}

1. Cardoso R, Knijnik L, Whelton SP, Rivera M, Gluckman TJ, Metkus TS, Blumenthal RS, McEvoy JW. Dual versus single antiplatelet therapy after coronary artery bypass graft surgery: an updated meta-analysis. Int J Cardiol 2018; 269: 80-88.

2. Berger JS, Frye CB, Harshaw Q, Edwards FH, Steinhubl SR, Becker RC. Impact of clopidogrel in patients with acute coronary syndromes requiring coronary artery bypass surgery: a multicenter analysis. J Am Coll Cardiol 2008; 52: 1693-1701.

3. Airoldi G, Campanini M. Ticagrelor. Ital J Med 2011; 5: 55-62.

4. Valgimigli $M$, Bueno $H$, Byrne RA, Collet JP, Costa F, Jeppsson A, Jüni $P$, Kastrati A, Kolh P, Mauri L, Montalescot G, Neumann FJ, Petricevic M, Roffi M, Steg PG, Windecker S, Zamorano JL, Levine GN, ESC Scientific Document Group; ESC Committee for Practice Guidelines (CPG); ESC National Cardiac Societies. 2017 ESC focused update on dual antiplatelet therapy in coronary artery disease developed in collaboration with EACTS: The Task Force for dual antiplatelet therapy in coronary artery disease of the European Society of Cardiology (ESC) and of the European Association for Cardio-Thoracic Surgery (EACTS). Eur Heart J 2018; 39: 213-260.

5. von Sheidt M, Bongiovanni D, Tebbe U, Nowak B, Stritzke J, Zhao O Zhu Y, Kastrati A, Cassese S, Schunkert H. Ticagrelor-based antiplatelet regimens in patients treated with coronary artery bypass grafting: a meta-analysis of randomized controlled trials. Eur J Cardiothorac Surg 2020; 57: 520-528.

6. Wallentin L, Becker RC, Budaj A, Cannon CP, Emanuelsson H, Held C, Horrow J, Husted S, James S, Katus H, Mahaffey KW, Scirica BM, Skene A, Steg PG, Storey RF, Harrington RA, PLATO Investigators; Freij A, Thorsén M. Ticagrelor versus clopidogrel in patients with acute coronary syndromes. N Engl J Med 2009; 361: 1045-1057.

7. Gurbel PA, Bliden KP, Butler K, Tantry US, Gesheff T, Wei C, Teng R, Antonino MJ, Patil SB, Karunakaran A, Kereiakes DJ, Parris C, Purdy D, Wilson V, Ledley GS, Storey RF. Randomized double-blind assessment of the ONSET and OFFSET of the antiplatelet effects of ticagrelor versus clopidogrel in patients with stable coronary artery disease: the ONSET/OFFSET study. Circulation 2009; 120: 2577-2585.

8. Hansson EC, Malm CJ, Hesse C, Hornestam B, Dellborg M, Rexius H, Jeppsson A. Platelet function recovery after ticagrelor withdrawal in patients awaiting urgent coronary surgery. Eur J Cardiothorac Surg 2017; 51: 633-637.
9. Varenhorst C, Alström U, Scirica BM, Hogue CW, Åsenblad N, Storey RF, Steg PG, Horrow J, Mahaffey KW, Becker RC, James S, Cannon CP, BrandrupWognsen G, Wallentin L, Held C. Factors contributing to the lower mortality with ticagrelor compared with clopidogrel in patients undergoing coronary artery bypass surgery. J Am Coll Cardiol 2012; 60: 1623-1630.

10. Hansson EC, Jeppsson A. Platelet inhibition and bleeding complications in cardia surgery: a review. Scand Cadiovasc J 2016; 50: 349-354.

11. Nardi P, Colella DF, Pisano C, Bassano C, Scafuri A, Bertoldo F, Buioni D, Ruvolo $\mathrm{G}$. Coronary artery bypass grafting on clopidogrel or ticagrelor therapy: interval of discontinuation and risk of bleeding. Kardiochir Torakochir Pol 2019; 16: 166-172.

12. Higgins TL, Estafanous FG, Loop FD, Beck GJ, Blum JM, Paranandi L. Stratification of morbidity and mortality outcome by preoperative risk factors in coronary artery bypass patients. JAMA 1992; 267: 2344-2348.

13. Tomšič A, Schotborgh MA, Manshanden JS, Li WW, de Mol BA. Coronary artery bypass grafting-related bleeding complications in patients treated with dual antiplatelet treatment. Eur J Cardiothorac Surg 2016; 50: 849-856.

14. Straus S, Haxhibeqiri-Karabdic I, Grabovica SG, Granov N. A difference in bleeding and use of blood and blood products in patients who were preoperatively on aspirin or dual antiplatelet therapy before coronary artery bypass grafting. Med Arch 2018; 72: 31-35.

15. Yende S, Wunderink RG. Effect of clopidogrel on bleeding after coronary artery bypass surgery. Crit Care Med 2001; 29: 2271-2275.

16. Hongo RH, Ley J, Dick SE, Yee RR. The effect of clopidogrel in combination with aspirin when given before coronary artery bypass grafting. J Am Coll Cardiol 2002; 40: 231-237.

17. Berger JS, Herout PM, Harshaw Q, Steinhubl SR, Frye CB, Becker RC. Bleedingassociated outcomes with preoperative clopidogrel use in on- and off-pump coronary artery bypass. J Thromb Thrombolysis 2012; 34: 56-64.

18. Mahla E, Suarez TA, Bliden KP, Rehak P, Metzler H, Sequeira AJ, Cho P, Sell J, Fan J, Antonino MJ, Tantry US, Gurbel PA. Platelet function measurement-based strategy to reduce bleeding and waiting time in clopidogreltreated patients undergoing coronary artery bypass graft surgery: the timing based on platelet function strategy to reduce clopidogrel-associated bleeding related to CABG (TARGET-CABG) study. Circ Cardiovasc Interv 2012; 5: 261-269.

19. Russo JJ, James TE, Ruel M, Dupuis JY, Singh K, Goubran D, Malhotra N, Rubens F, Chong AY, Hibbert B, Boland P, Tran DT, Tanguay JF, Lordkipanidzé M, Perrault L, Wells GA, Bourke M, Chan V, So DY. Ischemic and bleeding outcomes after coronary artery bypass grafting among patients initially treated with a P2 $\mathrm{Y}_{12}$ receptor antagonist for acute coronary syndromes: Insights on timing of discontinuation of ticagrelor and clopidogrel prior to surgery. Eur Heart J Acute Cardiovasc Care 2019; 8: 543-553.

20. Schotola H, Bräuer A, Meyer K, Hinz J, Schöndube FA, Bauer M, Mohite PN, Danner BC, Sossalla S. Perioperative outcomes of cardiac surgery patients with ongoing ticagrelor therapy: boon and bane of a new drug. Eur J Cardiothorac Surg 2014; 46: 198-205.

21. Hansson EC, Rexius H, Dellborg M, Albertsson P, Jeppsson A. Coronary artery bypass grafting-related bleeding complications in real-life acute coronary syndrome patients treated with clopidogrel or ticagrelor. Eur J Cardiothorac Surg 2014; 46: 699-705.

22. Gherli R, Mariscalco G, Dalén M, Onorati F, Perrotti A, Chocron S, Verhoye JP, Gulbins H, Reichart D, Svenarud P, Faggian G, Santarpino G, Fis chlein T, Maselli D, Dominici C, Musumeci F, Rubino AS, Mignosa C, De Feo M Bancone C, Gatti G, Maschietto L, Santini F, Nicolini F, Gherli T, Zanobini M, Kinnunen EM, Ruggieri VG, Rosato S, Biancari F. Safety of preoperative use of ticagrelor with or without aspirin compared with aspirin alone in patients with acute coronary syndromes undergoing coronary artery bypass grafting. JAMA 2016; 1: 921-928.

23. Vuilliomenet T, Gebhard C, Bizzozero C, Glauser S, Blum S, Buser A, Bolliger D, Grapow MTR, Siegemund M. Discontinuation of dual antiplatelet therapy and bleeding in intensive care in patients undergoing urgent coronary artery bypass grafting: a retrospective analysis. Interact Cardiovasc Thorac Surg 2019; 28: 665-673.

24. Holm M, Biancari F, Khodabandeh S, Gherli R, Airaksinen J, Mariscalco G, Gatti G, Reichart D, Onorati F, De Feo M, Santarpino G, Rubino AS, Maselli D, Santini F, Nicolini F, Zanobini M, Kinnunen EM, Ruggieri VG, Perrotti A, Rosato $S$, Dalén $M$. Bleeding in patients treated with ticagrelor or clopidogrel before coronary artery bypass grafting. Ann Thorac Surg 2019; 107: 1690-1698.

25. Knapik P, Knapik M, Zembala MO, Przybyłowski P Nadziakiewicz P, Hrapkowicz T, Cieśla D, Deja M, Suwalski P, Jasiński M, Tobota Z, Maruszewski BJ, Zembala M; KROK Investigators. In-hospital and mid-term outcomes in patients reoperated on due to bleeding following coronary artery surgery (from the KROK Registry). Interact CardioVasc Thorac Surg 2019; 29: 237-243. 